\title{
Modified Overall Immune Related Response Criterion, New Non-Measurable Lesion
}

National Cancer Institute

\section{Source}

National Cancer Institute. Modified Overall Immune Related Response Criterion, New

Non-Measurable Lesion. NCI Thesaurus. Code C111083.

The finding of a growth smaller than $5 \mathrm{~mm} \times 5 \mathrm{~mm}$ that was not present at the previous evaluation. Its presence does not indicate disease progession but precludes a determination of complete remission based on the modified overall immune related response criteria. 